\title{
Real sitio de Covadonga: una joya para la corona.
}

\author{
Real site of Covadonga: a jewel for the crown.
}

\author{
Ana Mạ Lobeto Álvarez ${ }^{1}$ \\ Universidad de Oviedo \\ alobetoalvarez@gmail.com \\ Recepción: 14/05/2018 Revisión: 03/06/2018 Aceptación: 18/06/2018 Publicación: 30/06/2018
}

\section{Resumen}

Covadonga une a su significado histórico y religioso, un profundo valor simbólico en relación al poder regio. La Corona descubrió a partir del reinado de Isabel II, el intenso efecto comunicador que para la dinastía podía tener la visita al Real Sitio. Isabel II, Alfonso XII y Alfonso XIII protagonizaron visitas acompañados por los príncipes de Asturias, y estos también lo hicieron en solitario. En todos los casos, se combinaron los actos religiosos con el adecuado y efectivo efecto comunicador, propiciando la identificación de la dinastía con los orígenes históricos del reino. La imposición de las insignias como príncipe de Asturias a Felipe de Borbón en 1977, indicaría una misma intención por parte de la dinastía recién instaurada de Juan Carlos, necesitada de legitimación histórica y, sobre todo, institucional.

Palabras claves: Borbones, corona, Covadonga, simbología, comunicación.

\section{Abstract}

Covadonga unites its historical and religious significance, a deep symbolic value in relation to the royal power, which was discovered in times of the reign of Isabel II, and the intense communicative effect that for the dynasty could have the visit to the Royal Site. Elizabeth II, Alfonso XII and Alfonso XIII carried out visits accompanied by the princes of Asturias, and also by themselves. In all cases, religious acts were combined with the appropriate and effective communicative effect, propitiating the identification of the dynasty with the historical origins of the kingdom. The imposition of the insignia as Prince of Asturias to Felipe

\footnotetext{
${ }^{1}$ Licenciada en Geografía e Historia y DEA por la Universidad de Oviedo, profesora de Dirección de Eventos en la Facultad de Turismo de Oviedo. Su línea de investigación está orientada a la imagen del poder y el ceremonial, iniciada con el trabajo de investigación "La Comunicación Política de los Príncipes de Asturias en la Edad Media". En estos momentos, redacta su tesis sobre la imagen y comunicación de las figuras regias en el Principado. Contacto: Blancanieves, 533980 Pola de Laviana (Asturias). E-mail: alobetoalvarez@gmail.com.
} 
de Borbón in 1976, would indicate the same intention on the part of the recently established dynasty of Juan Carlos I, in need of historical legitimation and, above all, institutional.

Keywords: Borbones, crown, Covadonga, symbology, communication.

\section{Sumario}

1. Covadonga: un escenario para las visitas regias

2. Visitas a Covadonga durante los reinados de Isabel II, Alfonso XII y Alfonso XIII

3. La investidura de Felipe de Borbón como Principe de Asturias en Covadonga

4. Conclusiones

5. Fuentes impresas

\section{COVADONGA: UN ESCENARIO PARA LAS VISITAS REGIAS}

El Real Sitio de Covadonga, en el Principado de Asturias, es santuario religioso y lugar de peregrinación para los fieles y devotos de su Virgen. En el año 2018 celebra una triple conmemoración: 1300 años de la batalla y 100 de dos eventos que significaron la culminación de años de preparativos: la coronación de la Virgen y la creación del Parque Nacional de la Montaña de Covadonga. Tres hitos que son a su vez, símbolo de los tres valores que identifican a Covadonga:

- El valor histórico: escenario de un suceso o acontecimiento histórico sobre el que se tienen pocos datos objetivos, pero que sirvió de base para el desarrollo histórico posterior de los Reinos de Asturias, Castilla y España.

- El valor religioso: en el lugar se encuentra el santuario de la Santina o Virgen de Covadonga.

- El valor natural: integrado en el Parque Nacional de los Picos de Europa.

Además, Covadonga ha sido escenario de importantes ceremonias y actos protocolarios protagonizadas por los monarcas. El protocolo y el ceremonial fueron -y siguen siendo- instrumentos al servicio de las instituciones vinculadas al poder. Las dinastías reales que a lo largo de la Historia se han ido sucediendo, utilizaron como herramientas de comunicación y propaganda, ceremonias que contribuyeran al reforzamiento de su imagen y consolidación de su identidad, en función de los intereses de cada época. Con ayuda del simbolismo y la emblemática, se desarrollaron unos ritos cuyo carácter fue variando por el obligado esfuerzo de adaptación, pero que en esencia, contienen como rasgos propios la exaltación de la imagen y la identificación de esta con la cultura de la sociedad de la que es representante. La función de las visitas regias es, en este sentido, fundamental, pues propicia el contacto directo de la Corona con el pueblo, aquel del que es soberano y del que recibe la soberanía. 
El Principado de Asturias fue visitado en varias ocasiones por los monarcas medievales pero, tras la inesperada arribada de Carlos I en 1516, se inició un largo paréntesis durante el que los Austrias no traspasarían las fronteras de la cordillera cantábrica. Las causas fueron fundamentalmente la dificultad de las comunicaciones, pero también la inexistencia de fueros propios que los monarcas debieran jurar, como era el caso de otros reinos de la Península, a los que se unía la existencia del título de "Príncipe de Asturias", creado en 1388 por Juan I, que a pesar de la solemnidad determinada por el "asiento en trono, manto de púrpura, sombrero en la cabeza, vara de oro en la mano, beso de paz y proclamación como Príncipe de Asturias" - tal y como relatan los documentos de la época no se vio acompañada por una acción directa del príncipe o princesa en el territorio.

La tendencia variaría a partir de mediados del siglo XIX. Las difíciles condiciones políticas a las que se tuvo que enfrentar Isabel II, obligaron a sus gobiernos a diseñar unos programas propagandísticos orientados a acercar la imagen y persona de la soberana a sus súbditos. Las visitas se extendieron por varias regiones españolas, siendo el viaje que realizó a las provincias del norte en 1858 , el que mejor definiría un modelo que sería repetido por los monarcas posteriores, hasta la actualidad: entrada en las ciudades y pueblos más emblemáticos, visita a las instituciones más importantes, recepción por parte de las autoridades, contacto con el pueblo y con representantes de los diferentes ámbitos, identificación con la cultura, tradiciones y folclore del lugar. No es de extrañar que en estos itinerarios, Covadonga ocupara un papel protagonista, convirtiéndose su visita en una actividad obligada para los viajes regios que se sucedieron no sólo durante el reinado de Isabel II, sino también en los de Alfonso XII y Alfonso XIII. Por ello, entre 1857 y 1928 tienen lugar varias visitas regias a Covadonga, protagonizadas por reyes y reinas, príncipes y princesas, infantes e infantas, que pueden ser estudiadas a través de la consulta en varios tipos de fuentes:

- Los temas referidos a su organización, implicación con las instituciones y autoridades asturianas y, sobre todo, financiación, aparecen reflejados en las actas de la Junta General del Principado, que, con motivo de cada visita, debía nombrar comisionados, acordar presupuesto y, sobre todo, lograr su ejecución en el tiempo y forma establecido.

- Los cronistas y la prensa de la época informan sobre aspectos referidos al programa, los acompañantes, y las reacciones populares.

- Las fuentes iconográficas -imágenes publicadas en prensa y crónicas- muestran imágenes referidas a la puesta en escena.

\section{VISITAS REGIAS A COVADONGA DURANTE LOS REINADOS DE ISABEL II, ALFONSO XII Y ALFONSO XIII}

La primera de las visitas regias no fue protagonizada por Isabel, sino por los duques de Montpensier, matrimonio formado por Antonio de Orleans -hijo de Luis Felipe I de Francia- y María Luisa Fernanda de Borbón -hermana de Isabel II-, en junio de 1857, 
acompañados por su hija Isabel y un grupo de damas y gentileshombres de la corte. La prensa $^{2}$ describe en sus crónicas los pormenores de la visita: la llegada de los duques a la iglesia bajo palio y en procesión, acompañando a la imagen de la Virgen; la entrega de diversas ofrendas realizadas por la Real Fábrica de Platería, de Madrid; el almuerzo en la sala capitular de la colegiata, la visita de los lugares emblemáticos de Covadonga, y la inauguración del monumento dedicado a Pelayo, en el que figuraba la siguiente inscripción:

En este campo del Repelao, después de la victoria de Covadonga anunciada por la aparición de la Santa Cruz, fue proclamado rey don Pelayo. Los señores infantes de España duques de Montpensier, en su viaje a Asturias y visita a Covadonga el día 15 de junio de 1857, mandaron erigir a sus expensas este obelisco que se inauguró... ${ }^{3 .}$

Con ocasión de esa visita, se anunció la que se iba a celebrar al año siguiente, de carácter más importante, pues correspondería a la propia reina, acompañada del resto de la familia real. La visita de Isabel II a Covadonga se celebró en el marco de un viaje oficial a Asturias, León y Galicia, del que se dispone de una minuciosa información, gracias a la edición de un libro que detalla día a día el apretado programa: es la Crónica del Viaje de Isabel II a Asturias, León y Galicia, escrito por Juan de Dios de la Rada y Delgado ${ }^{4}$, en cuyo capítulo titulado "De Gijón a Covadonga" ${ }^{5}$ se puede leer una detallada descripción de la visita, considerada por el autor de gran trascendencia, pues era "uno de los principales motivos de su viaje a Asturias" ${ }^{\prime}$. La reina, acompañada por su esposo Francisco de Asís y de sus hijos el príncipe de Asturias don Alfonso y la Infanta Isabel, pasó veintidós días en el Principado, dedicando las jornadas no sólo al ocio - baños de mar, paseos, teatro, bailes-, sino también al trabajo -visitas a mina y fábrica de Arnao - y, cómo no, la visita a otras ciudades -Oviedo y Avilés- y lugares emblemáticos, como Covadonga, donde además se celebraría la confirmación del príncipe de Asturias.

Teniendo en cuenta el carácter propagandístico del viaje, se puede decir que la visita a Covadonga fue una de las más importantes. Al ser la primera ocasión en la que un monarca español visitaba el santuario ${ }^{7}$, fueron necesarias importantes obras en relación a la mejora del acceso, promoviéndose el acceso al lugar el día 28 de agosto, fecha escogida para la visita real.

Rada y Delgado -propagandista de la monarquía y por tanto, transmisor de una imagen de "aceptación universal"- se refiere a una "multitud de personas" de todas las

\footnotetext{
${ }^{2}$ El genio de la libertad. Periódico de la tarde, no 159. 1857, julio, 2 (página 3 de 4).

3 La inscripción aparece mencionada en el diario "La Cruz: revista religiosa de España y demás países católicos". 1880, dic. 19, pág. 722 y en “Covadonga, Sta. María la Real de": Gran Enciclopedia Asturiana, Tomo 5. Gijón: Editorial Silverio Cañada, 1970, pág. 173.

${ }^{4}$ Juan de Dios de la Rada y Delgado (1860): Viaje de SS.MM. y AA. por Castilla, León, Asturias y Galicia verificado en el verano de 1858. Madrid: Aguado.

${ }^{5}$ pp. 528-566.

${ }^{6}$ Rada y Delgado: Obr. cit. pág. 594.

${ }^{7}$ Y la primera vez que un rey pisaba el Principado, desde la llegada de Carlos I, como bien indica Rada y Delgado (obr. cit.pág. 318).
} 
clases sociales, como espectadores de la visita y ofrece un detallado informe del programa del día, que se inició a las nueve de la mañana: entrada de la reina a través de un arco de ramaje, situado en el punto desde el que se podía ver de frente la cueva y lenta ascensión a pie con el príncipe de Asturias en los brazos. Fue recibida con palio a la entrada de la iglesia y en la cueva se ofició una misa a cargo del arzobispo de Cuba, Patriarca de las Indias. Después se celebraría la ceremonia de la confirmación del príncipe de Asturias y la infanta, apadrinados por el obispo de Oviedo y la duquesa de Alba respectivamente. La ceremonia, escenificada delante de los sepulcros reales, tiene un valor simbólico muy alto, llamando la atención el hecho de que don Alfonso no había cumplido su primer año de vida y por tanto, no había recibido aún la comunión.

Tras un almuerzo celebrado en la sala capitular, la comitiva -precedida por el presidente del Consejo de Ministros, que portaba el estandarte de la Virgen, se dirigió en procesión a la explanada del monte para asistir a la misa oficiada por el obispo de Oviedo, en la que se estrenó uno de los pontificales que fue donado en nombre del príncipe de Asturias con ocasión de la visita.

De todo ello, quedó testimonio en una lápida de mármol blanco, en la que se inscribió el siguiente texto:

El día 28 de agosto de 1858 visitaron esta sagrada cueva S. M. y AA. RR. la Reina de España Da Isabel II, su augusto esposo don Francisco de Asís y los Serenísimos señores don Alfonso, Príncipe de Asturias y Da María Isabel Francisca de Asís, Infanta de España. En dicho día y en este mismo sitio les fue administrado a SS. AA. RR. el sacramento de la confirmación.

Los años siguientes iban a ser muy intensos en España. Diez años después de la visita de Isabel II a Covadonga, triunfa otra revolución, la "Gloriosa", que envía a la reina al exilio. Seis años más tarde, se acuerda la restauración borbónica en la figura de Alfonso, príncipe de Asturias, quien regresa a España como rey, plenamente consciente de la importancia de ser conocido y querido por los españoles. Una nueva ocasión de diseñar un programa de propaganda y, por tanto, una nueva visita a Covadonga, que será la segunda y última de su vida, que también hace acompañado de su hermana Isabel, ahora Princesa de Asturias. La visita se celebra nueve años después del derrumbe de la montaña causante de la destrucción de una parte importante de la Colegiata $^{8}$, lo que generaría una nueva causa de vinculación entre la Corona y Covadonga, derivada de la necesidad de llevar a cabo el intenso programa de restauración necesario.

La visita al Principado se celebra entre los meses de julio y agosto de 1877. De ella existe una crónica detallada en el artículo de prensa "Viaje de S.M. el Rey a las Provincias del Noroeste" ${ }^{\prime \prime}$ y como en el caso anterior, Gijón será el centro de operaciones, con el palacio del marqués de Revillagigedo como residencia real. Combinando el ocio con el trabajo, se

\footnotetext{
${ }^{8}$ Gran Enciclopedia Asturiana, obr. cit. pág. 173.

${ }^{9}$ La llustración española y americana, no XXX, año XXI. 1877, agosto, 15, pp.. 90-91.
} 
aprovecha para que el monarca realice una intensa visita a Oviedo -catedral, hospital, hospicio, universidad, Cuartel de Santa Clara- e incluso un viaje a Galicia, por mar.

Crabiffose ${ }^{10}$ recoge varios de los pormenores de la visita al Real Sitio, que tiene lugar el día 21. El rey y su hermana acuden acompañados de autoridades oficiales: varios ministros, el capitán general de Castilla la Vieja y autoridades asturianas. La primera parte de la visita se desarrolló en la iglesia de la colegiata, encaminándose después a la cueva. Al día siguiente, participaron en una procesión encabezada por los marqueses de Camposagrado y el barón de Covadonga, quienes portaban la imagen, que fue conducida desde la iglesia de la colegiata hasta la capilla del Campo. Desde allí se dirigieron al "Cuetu" donde se procedió a la inauguración del inicio de las obras del templo monumental que iba a ser construido, ya proyectado por el señor obispo y para cuya erección se consignaron unos donativos en el álbum abierto al efecto. El rey expidió la Real Orden por la que se aprobaban el proyecto y planos del templo' entregando un donativo de 25.000 pesetas, junto a otro de su hermana la infanta, de 12.000, para contribuir a los gastos de construcción. Constantino Cabal escribe que "aquel día se celebraron en Covadonga grandes fiestas" ${ }^{11}$, amenizadas por el sonido de la gaita y la voz de los aldeanos ${ }^{12}$.

Reinando Alfonso XII, se produce otra visita en la que los príncipes de Austria y Baviera actúan como representantes del rey. Es en junio de 1879, dos años después de la anterior, y al tratarse de figuras de menor categoría, tiene menor repercusión en las crónicas de la época. Las actas de la Diputación informan tan sólo sobre unas cuentas que presenta el ayuntamiento de Ribadesella en relación a los gastos ocasionados por la estancia de la pareja, que se celebró el 7 de junio ${ }^{13}$

Alfonso XII muere con 28 años y pocos meses después, nace su hijo, también llamado Alfonso. Los primeros años de su vida, ejerce Ma Cristina la Regencia. Cuando cumple 16 años, en 1902, es coronado, programándose un viaje institucional a Asturias, tierra que ya había visitado previamente, acompañado por su hermana Mercedes, la princesa de Asturias, y el esposo de ésta. La visita a Asturias es detallada en dos artículos publicados en La Ilustración española y americana, de los que el primero, titulado El primer viaje de Alfonso XIII contiene información referida a la visita a Covadonga, celebrada en dos jornadas, 2 y 3 de agosto ${ }^{14 .}$

La visita a Covadonga iba a tener de nuevo un protagonismo especial. El autor de los artículos, Carlos Luis de Cuenca, destaca la "espontaneidad sincera con que todos se disponían a recibir a su Rey", que entró en Cangas de Onís a través de un arco de columnas decorado con leones y escudos de España, en el que se podía leer "La corte de Pelayo a su

\footnotetext{
${ }^{10}$ Francisco Crabiffosse Cuesta (2004): “Identidad y compromiso. Covadonga y la dinastía Borbón”, en Visitas Regias. Puerto de Gijón. Edición crítica comisariada por Gracia Suárez Botas. Asturias: Puerto de Gijón, pág. 40.

${ }^{11}$ Constantino Cabal (1918): Covadonga. Madrid, Imprenta de Gabriel López de Horno, pág. 373.

${ }^{12}$ Cita Constantino Cabal a Fernando f. Rosete, autor de Pelayo y Covadonga. 1909, pág. 75.

${ }^{13}$ A.H.P.A. Fondo J.G.P.A. Actas de la Diputación.

${ }^{14}$ La llustración española y americana, no XXX, año XLVI, 1902, agosto, 15 pp. 94-95.
} 
rey". El monarca, acompañado de los Príncipes de Asturias, llegó a Covadonga en un coche abierto tirado por mulas. A las puertas de la gruta, fue recibido por el prelado y el cabildo y escuchó el "Saludo del Obispo" y el Tedéum, tras el que se dirigió a pie la residencia episcopal. Se habían dispuesto grupos de jóvenes vestidos con la indumentaria tradicional asturiana, así como gaiteros, para que durante el día amenizaran el ambiente. Al día siguiente, participaría en una misa celebrada en el templo inaugurado el año anterior.

Serían frecuentes las visitas de Alfonso XIII al Principado, en cuyas costas el rey encontraba un escenario ideal para la participación en las regatas. Sin embargo, la visita realizada en 1918 tuvo un alto carácter institucional, siendo este año cuando se celebraron los tres acontecimientos señalados al inicio de este artículo. La visita tuvo lugar el 8 de septiembre, cuando se celebraría la coronación canónica de la Virgen en el duodécimo centenario de la Batalla de Covadonga. En la iniciativa de la conmemoración juega un papel importante el Excmo. Ayuntamiento de Cangas de Onís, que el 30 de julio de 1916, había dirigido un escrito al cronista de Asturias, don Fermín Canella, en el que le pedía "se digne dirigir una exposición a S.M. El Rey (q. D. g.), rogándole que con su augusto hijo el Serenísimo Príncipe de Asturias se sirva patrocinar el centenario"15. Canella intervino en el Senado en la sesión del 4 de diciembre de 1916, con un discurso en el que explicaba con detalle la propuesta de organización del centenario ${ }^{16}$. Tras la constitución en Oviedo, a principios de 1917, de la "Junta Provincial del Centenario", se empezaron a proponer un conjunto amplio de actividades, por parte del Cabildo, de la Diputación y del Gobierno de la Nación, que desde un principio contaron con el firme apoyo del rey. Entre otras, la solicitud, por parte de la Diputación, de la declaración de este aniversario como "fiesta nacional cívico-religiosa"17,. Además, el rey sancionó una ley, publicada en julio de 1918, por la que se declaraba el Parque Nacional de la Montaña de Covadonga y el reconocimiento de una especial protección por parte del Estado ${ }^{18}$.

A pesar de la dificultad para lograr la financiación del evento, se logró aprobar la cantidad de 300.000 pesetas para los gastos de solemnización del acontecimiento, que no sólo incluyen los derivados de festejos y ceremonias, sino que también proyectos de una serie de obras que se encargan con motivo de esta conmemoración: reforma del hospitalmanicomio, construcción de otro nuevo, monumento dedicado a Pelayo en Covadonga, un funicular a Cangas de Onís, construcción de un grupo escolar en Cangas de Onís....De nuevo se puede encontrar una crónica muy detallada en la prensa de la época: en el diario liberal "El Imparcial" ${ }^{19}$, y en "La Ilustración española y americana" ${ }^{20}$ se describen con gran detalle las jornadas, correspondientes a los días 7, 8 y 9 de septiembre:

\footnotetext{
${ }^{15}$ Fermín Canella (1998): De Covadonga. Contribución al XII Centenario. Edición facsimilar de la edición de 1918. Oviedo: Alvízoras Llibros, pág. 214.

${ }^{16}$ Canella. Obr. cit. pp.. 221-233.

${ }^{17}$ A.H.P.A. Fondo J.G.P.A. Actas de la Diputación.

${ }^{18}$ Canella. Obr. cit., pág. 277.

19 №18.511, año LII, 1918, agosto, 21 pág. 3.

${ }^{20}$ № 34, Año LXII, septiembre, 15, pp.. 510-511.
} 
El día 7 llegaron los Reyes y por la noche, se celebró una procesión con antorchas, con motivo de la vigilia de la Adoración Nocturna, en cuyo marco se trasladó la imagen de la Virgen desde la Cueva hasta la Basílica.

El día 8 se dedicaría al acto principal de coronación de la Virgen, además de la inauguración del Parque Nacional. El primero se inició con la salida de los reyes del hotel Pelayo y su entrada bajo palio en el templo. Se presentaron las coronas con las que iban a ser coronadas la Virgen y el Niño Jesús, en una bandeja cubierta por paño de terciopelo, de las que se hicieron cargo el abad y cabildo de la colegiata -levantándose acta notarial correspondiente-, fueron bendecidas y se inició la ceremonia, con misa de pontifical y procesión hasta la explanada de la basílica, dónde se procedió a la coronación, a la que asistieron los reyes desde la tribuna correspondiente.

El día 9, de nuevo en Oviedo, presidieron en el salón de la Diputación Provincial el acto conmemorativo de la batalla, en el que tuvo un papel especial Fermín Canella, como cronista de Asturias. Además, se inauguró una exposición de pintura y se celebró una corrida de toros.

Además de los actos institucionales, se diseñó un variado programa de actividades, que incluían la Exposición y Semana avícola, un certamen de orfeones, una fiesta asturiana, la actuación de una importante compañía de ópera y la amenización por parte de bandas de música, entre las que también se contaba la de Madrid.

Aún tendrían lugar dos últimas visitas, realizadas por dos de los hijos de Alfonso XIII y Victoria Eugenia y datadas en los años 1925 y 1928. La primera es protagonizada por don Alfonso, príncipe de Asturias, quien, con dieciocho años, realiza una visita con carácter instructivo, para arraigar en él la vinculación con Asturias. Además de visitar Oviedo, Gijón, Avilés y otras poblaciones, conoce las explotaciones de carbón y los valles mineros del Caudal y del Nalón, llegando a bajar al pozo de la mina de El Fondón, en Sama de Langreo. También se desplaza a Covadonga, donde fue nombrado "canónigo honorario" por el cabildo, cargo honorífico que compartió con su padre, el rey. Tras su renuncia como Príncipe de Asturias, en 1933, su padre le asignaría el título de "Conde de Covadonga", con el que viajaría por el mundo hasta su muerte en 1938.

En cuanto a la última visita, tiene lugar en 1928 y es protagonizada por don Jaime, el segundo de los hijos del rey, quien en el mes de abril visita Asturias, también con un amplio programa $y$, aunque la realizada a Covadonga aparece mencionada en prensa, se ofrecen muy pocos detalles, no apareciendo ninguna referencia en las actas de la Diputación.

\section{LA INVESTIDURA DE FELIPE DE BORBÓN COMO PRÍNCIPE DE ASTURIAS EN COVADONGA}

El título de Príncipe de Asturias, la venera acreditativa de tal distinción y el simbólico tributo para mantillas, fueron los distintivos que don Luis Sáenz de Santamaría - presidente de la Diputación de Asturias en 1977- entregó a don Felipe de Borbón y Grecia, como señal de reconocimiento de la Corporación provincial a la institución del Principado de Asturias. El 
acto se celebró en la explanada de la basílica del Real Sitio de Covadonga, enmarcado en la visita que los reyes de España, don Juan Carlos y doña Sofía, hicieron el primero de noviembre, acompañados también de sus hijas, las infantas Elena y Cristina, y las hermanas del rey, doña Margarita y doña Pilar. La jornada se celebró según un elaborado programa que comprendía todos los elementos característicos de una visita regia, repartidos entre los actos protocolarios, la ceremonia religiosa y el acto de entrega de las distinciones. Sobre todo, constituyó un ejemplo de la habilidad propagandística de los entonces responsables de comunicación de la Casa Real, que supieron ver en el Real Sitio de Covadonga, el lugar ideal para el primer "baño de masas" del heredero de la Corona.

La investidura de Felipe de Borbón y Grecia con los atributos de Príncipe de Asturias, en Covadonga, tuvo por tanto un carácter excepcional y único en la historia de España. Ello no resulta extraño en el especial contexto político en el que se desenvolvían los primeros capítulos de una dinastía recién instaurada, que consolidaba la continuidad, tan solo seis meses después de la renuncia expresa al derecho al trono de quien había sido el jefe de la Casa y su heredero natural, don Juan de Borbón, sin una Constitución que regulara todo lo referido a la Corona. El protocolo y el ceremonial se aliaron con la Historia y convirtieron Covadonga en un escenario ideal para la presentación del príncipe, en la que los ciudadanos participaron de forma entusiasta, por lo que significaba de renovación institucional.

\section{CONCLUSIONES}

Los monarcas Borbones y sus descendientes, acudieron a Covadonga en varias ocasiones, alimentando la consideración del Real Sitio como lugar emblemático de la historia de Asturias y de España, estrechamente vinculado a la Corona. Cuando en 1925 se produce la última visita regia anterior a la proclamación de la Segunda República - protagonizada por don Alfonso, Príncipe de Asturias- se puede decir que el lugar de Covadonga -al que se atribuye ser escenario del principio de la Reconquista - se ha consolidado como referente histórico y simbólico de vinculación entre la Monarquía y Asturias.

En 1977 se celebró en Covadonga un acontecimiento histórico con un único precedente en el tiempo: Felipe de Borbón recibió las insignias de Príncipe de Asturias. Sólo su tatarabuelo -Alfonso, hijo de Isabel II, quien iba a ser Alfonso XIII- las había recibido en el mismo lugar. Covadonga se consolidaba como lugar de referencia también para la dinastía instaurada de Juan Carlos I, cuyos constructores encontraron en este santo e histórico lugar, el perfecto eslabón para reforzar la unión con el pasado.

\section{FUENTES IMPRESAS}

\section{Prensa}

El genio de la libertad. Periódico de la tarde, 1848- (Palma de Mallorca: [Imp. de Pedro Gelabert]). 
La Cruz: revista religiosa de España y demás países católicos, 1852-1916 (Sevilla: [Madrid: Imp. de la Esperanza, [1872

La llustración española y americana, 1869-1921- (Madrid: [Imprenta de T. Fortanet])

\section{Bibliografía}

CABAL, Constantino: Covadonga. Madrid, Imprenta de Gabriel López del Horno, 1918.

CANELLA Y SECADES, Fermín: De Covadonga. Contribución al XII Centenario. Edición facsimilar de 1918. Oviedo: Alvízoras Llibros, 1998.

DE LA MADRID ÁLVAREZ, VIDAL (coord.): El santuario de Nuestra Señora de Covadonga.

Gran Enciclopedia Asturiana.Tomo 5, Gijón, DL 1976.

RADA Y DELGADO, JUAN DE DIOS DE LA: Viaje de SS.MM. y AA. por Castilla, León, Asturias y Galicia verificado en el verano de 1858. Madrid: Aguado, 1860.

RIEGO, BERNARDO: "Imágenes fotográficas y estrategias de opinión pública: los viajes de Isabel II por España (1858-1866)" en Reales Sitios. Revista del Patrimonio Nacional, no 139, 1999.

RUÍZ DE LA PEÑA GONZÁLEZ, I.: "El templo de Nuestra Señora de Covadonga en la visita de D. Jerónimo de Chiriboga (1613), en Sulcum sevit. Estudios en homenaje a Eloy Benito Ruano, vol. II, Oviedo, 2004, pp. 635-654.

SANZ FUENTES, M.J.: "Los más antiguos documentos originales de Covadonga", en M.I. del Val Valdivieso y P. Martínez Sopena (dirs.): Castilla y el mundo feudal. Homenaje al profesor Julio Valdeón, vol. I, Valladolid, 2009, pp. 181-192.

VV.AA: Covadonga: Iconografía de una devoción: exposición conmemorativa del centenario de la dedicación de la Basílica de Covadonga (1901-2001). Covadonga, 2001.

Visitas regias. Puerto de Gijón. Edición científica comisariada por Gracia Suárez Botas. Asturias: Puerto de Gijón, 2004.

This work is licensed under a 